\title{
Lyophilized Black Raspberry Saliva Substitute
}

National Cancer Institute

\section{Source}

National Cancer Institute. Lyophilized Black Raspberry Saliva Substitute. NCI Thesaurus. Code C99164.

A saliva substitute (or artificial saliva) containing lyophilized black raspberry with potential antioxidant, pro-apoptotic and chemopreventive activities. In addition to vitamins, minerals and phytosterols, black raspberries are rich in flavonols of which the anthocyanins appear to contribute significantly to this agent's chemopreventive effects. Anthocyanins inhibit the activation of several signal transduction pathways, including the mitogen-activated protein kinase-mediated pathways, and certain transcription factors, such as nuclear factor kappa B (NF-kB), activator protein-1 (AP-1) complex, and nuclear factor in activated T-cells (NFAT). This in turn modulates the expression of downstream target genes that are upregulated in a variety of cancer cell types, including inducible nitric oxide synthase, cyclooxyg enase-2, vascular endothelial growth factor and the antiapoptotic protein survivin. 